\title{
CONTROLLED RELEASE OF GABAPENTIN THROUGH RETICULATED CHITOSAN AND HYDROXYETHYL CELLULOSE HYDROGEL MATRIX TABLETS
}

\author{
Narasimha S. Managoli ${ }^{1,4}$, Raghavendra V. Kulkarni ${ }^{2}$, , Nadendla Ramarao ${ }^{3}$, \\ Iranna S. Muchandi ${ }^{1}$
}

\begin{abstract}
1BVVS's HSK College of Pharmacy, Bagalkot-587101, Karnataka, India. 2BLDEA's College of Pharmacy BLDE University Campus, Bijapur-586101, India. ${ }^{3}$ Chalapati Institute of Pharmaceutical Scie, Guntur 522034, Pradesh, India. ${ }^{4}$ Acharya Nagarjun University, Nagarjunanagar, Guntur 522510, Andhra Pradesh, India
\end{abstract}

Submitted: 02-01-2014

Revised: 04-04-2014

Accepted: 20-06-2014

*Corresponding author

Raghavendra V. Kulkarni

Email :

rvkulkarni75@yahoo.com

\section{INTRODUCTION}

Hydrogels are called as three dimensional hydrophilic networks which can absorb large amount of water or biological fluids; they are chemically stable and may undergo degradation and finally disintegrate and dissolve in water or biological fluids. To avoid this dissolution/degradation, a controlled reticulation (crosslinking) can be provided during the preparation of the hydrogels (Singh et al., 2006). Recently, much importance has been given to the preparation of hydrogels from natural polymers (Hoffman et al., 2002). Among natural polymers, chitosan, a linear polysaccharide, has been reported to be good for synthesizing hydrogels because of its greater crosslinking ability due to the presence of amino groups on its backbone (Ravi Kumar et al.,). The major limitation of chitosan in drug delivery is its poor water solubility and rapid swelling in acidic conditions that leads to burst release of drugs. To overcome these limitations, several modifications have been attempted such as crosslinking, preparation of derivatives etc.
(Chen et al., 2004). Biodegradability and biocompatibility of chitosan has prompted the researchers to explore it in a variety of areas such as medicine, drug delivery, tissue engineering, antimicrobial agents, textiles, chromatography, metal chelation, and other industrial as well as biomedical applications (Gong et al., 2000, Kim et al., 1992, Drury et al., 2003, Zhao et al., 2003). Many methods have been reported for the crosslinking of chitosan, such as chemical crosslinking with glutaraldehyde, blocked diisocyanate (LinGibson et al., 2003) and with Mo (IV) polyoxyanions (Draget et al., 1992). Among all these, chemical crosslinking methods seem to be a better approach to improve the strength of hydrogels.

The oral route of drug administration has received the most attention as it is uncomplicated, convenient and safer (Mutalik et al., 2008). Controlled release matrix tablets are among the most popular delivery systems for oral controlled release dosage forms. These matrix tablets are generally accepted because of 
their advantages over conventional dosage forms. They show distinct modulation in drug release as a result of hydration of the constituent polymer, flexibility to obtain desired drug release profiles, cost effectiveness, patient compliance, providing a constant, prolonged, and uniform drug release and more important is acceptability by Food and Drug Administration (FDA). The swelling behavior and erosion of hydrogel matrix in aqueous media are very crucial in getting the desired drug release and are affected by the crosslinking of polymer and other formulation compositions (Pavithra et al., 2010).

Gabapentin (GBP) is an analog of $\gamma$-aminobutyric acid (GABA), which is presently given as an adjunctive therapy for partial seizures with epilepsy and also for post herpetic neuralgia. GBP has a relatively short half-life of $5 \mathrm{~h}$ that requires repeated dosing. The repeated administration of GBP may leads to non-compliance in epilepsy patients. Hence, it would be better, if GBP is given as a controlled release (CR) tablet, which may provide prolonged release with greater efficacy and a reduced incidence of adverse effects (Bryans et al., 1999).

Hence, looking into the account of potential of chitosan, and GBP dosing, the present work was aimed to prepare matrix tablets using crosslinked chitosan and hydroxyethyl cellulose (HEC) for controlled release of GBP.

\section{MATERIALS AND METHODS}

Gabapentin (GBP) was obtained as a gift sample from Cipla Ltd. (Mumbai, India). Chitosan was procured from Vishu Aquatech, Madras, India. hydroxyethyl cellulose (HEC), acetaldehyde (AL), lactose, magnesium stearate, and starch were purchased from $\mathrm{s}$ d finechemicals Ltd (Mumbai, India). Double distilled water was used throughout the study. All other chemicals were of analytical grade and procured form local laboratory chemicals suppliers and used without further purification.

\section{Crosslinking of chitosan with acetaldehyde}

A $2 \% \mathrm{w} / \mathrm{v}$ chitosan $(\mathrm{CH})$ solution was prepared in $2 \% \mathrm{v} / \mathrm{v}$ aqueous acetic acid using a magnetic stirrer until the chitosan dissolved completely. To this polymeric solution, acetaldehyde (AL) (5\%, 10\%, 15\% and 20\% $\mathrm{w} / \mathrm{w}$ of dry chitosan; which were designated as CHAL1, CHAL2, CHAL3 and CHAL4 respectively), $0.5 \mathrm{~mL}$ of $0.1 \mathrm{~N} \mathrm{HCl}$ were added and stirred for $1 \mathrm{~h}$ at $50^{\circ} \mathrm{C}$. After $1 \mathrm{~h}$, the reaction mixture was cooled to room temperature, excess quantity of acetone was added and the precipitated hydrogel was repeatedly washed with distilled water to remove any unreacted material. Further, it was dried at $40^{\circ} \mathrm{C}$ for $24 \mathrm{~h}$; powdered and stored in a well closed container (Kulkarni et al., 2005).

\section{Preparation of hydrogel matrix tablets}

The matrix tablets were prepared by conventional wet granulation method. Accurately weighed quantities of GBP, crosslinked chitosan (CHAL1, CHAL2, CHAL3 and CHAL4), HEC, and microcrystalline cellulose (MCC) were passed through sieve \# 80 and mixed to get uniform mass. To this, sufficient amount of binding agent (starch paste $5 \% \mathrm{w} / \mathrm{v}$ ) was added. After required cohesiveness was attained, the mass was sieved through $22 / 44 \mathrm{mesh}$. The granules were dried at $40^{\circ} \mathrm{C}$ for $12 \mathrm{~h}$ and then kept in a desiccator for $12 \mathrm{~h}$ at room temperature. The granules retained on 44 mesh were taken and mixed with $10 \%$ of fines (granules that passed through 44mesh), talc and magnesium stearates were added as glidant and lubricants respectively and then compressed into tablets using a rotary tablet compression machine (Karnavati Minipress I, Ahmedabad, India). The total weight of tablets was $500 \mathrm{mg}$ which contain $100 \mathrm{mg}$ of GBP and other ingredients as summarized in table I. The granules were tested for pre-compression parameters like bulk density, tap density, packing ability and flow property. Finally, tablets were evaluated for weight variation, drug content, hardness, friability, equilibrium swelling and in vitro drug release.

\section{Fourier transform infrared (FTIR) spectroscopy \\ The CH, CHAL4, GBP and physical} mixture of GBP and other excipients were crushed with $\mathrm{KBr}$ to make pellets under hydraulic pressure of $600 \mathrm{~kg}$, and then the FTIR spectra were recorded between 4000 and $400 \mathrm{~cm}^{-1}$. 


\section{Differential scanning calorimetric (DSC) analysis}

The G2, G4, G5, G6 and G7 samples were taken in a sealed aluminum DSC pan and an empty aluminum pan was used as reference. The samples were heated in the range of 40$300^{\circ} \mathrm{C}$ at a heating rate of $10^{\circ} \mathrm{C} / \mathrm{min}$ under nitrogen atmosphere in a microcalorimeter (Perkin Elmer, Pyris 6 DSC, USA) and the thermograms were obtained.

\section{Thermogravimetric (TG) analysis}

The $\mathrm{CH}$, CHAL1, CHAL2 and CHAL3 samples were heated in the range of $20-600^{\circ} \mathrm{C}$ at a heating rate of $10^{\circ} \mathrm{C} / \mathrm{min}$ under argon atmosphere using a microcalorimeter (Perkin Elmer, USA) and thermograms were obtained.

\section{X-Ray diffraction studies}

The XRD spectra of the samples G2, G4, G5, G6 and G7 were recorded using a Philips, PW-171, X-ray diffractometer with CuNF filtered $\mathrm{CuK} \alpha$ radiation. Quartz was used as an internal standard for calibration. The Xray diffractometer was attached to a digital graphical assembly and computer with $\mathrm{Cu}-\mathrm{NF}$ $25 \mathrm{KV} / 20 \mathrm{~mA}$ tube as a $\mathrm{CuK} \alpha$ radiation source in the $2 \theta$ range $0-80^{\circ}$.

\section{Drug content uniformity}

Tablets were randomly selected and kept in $100 \mathrm{~mL}$ USP phosphate buffer of $\mathrm{pH} 7.4$ at $37^{\circ} \mathrm{C}$ for $12 \mathrm{~h}$. After $12 \mathrm{~h}$, tablets were crushed with glass rod, heated tenderly for $3 \mathrm{~h}$ to take out the drug from hydrogel matrix and then centrifuged to separate the polymeric debris. The clear solution was subjected for drug content analysis using UV-visible spectrophotometer (Model Pharmaspec UV-1700, Shimadzu, Japan) at $215 \mathrm{~nm}$.

\section{Equilibrium swelling study}

The equilibrium swelling of the hydrogel tablets was performed by mass measurement. Accurately weighed tablet was kept in with $100 \mathrm{~mL}$ phosphate buffer solutions of $\mathrm{pH} 1.2$ and 7.4 at $37^{\circ} \mathrm{C}$ for $8 \mathrm{~h}$. The tablets were taken out after $8 \mathrm{~h}$ and blotted carefully to remove surface liquid. The swollen tablets were weighed again using the electronic microbalance (Shimadzu, Japan) and the swelling ratio was calculated.

\section{In-vitro drug release}

The in-vitro drug release study was carried out using a USP-23 rotating dissolution tester. GBP release from the tablets was studied in $900 \mathrm{~mL}$ acidic medium $(\mathrm{pH} 1.2)$ for $2 \mathrm{~h}$ and in alkaline medium ( $\mathrm{pH} 7.4$ phosphate buffer) till end of the study at $37.0 \pm 0.5^{\circ} \mathrm{C}$ and $50 \mathrm{rpm}$ speed. At different time intervals, $5 \mathrm{~mL}$ aliquots were taken out and replaced with the same volume of fresh solution. The amount of drug released was analyzed using UV-visible spectrophotometer at $215 \mathrm{~nm}$.

Further, release data were fitted to various mathematical models such as Zero order release kinetics, Higuchi model, and Korsmeyer-Peppas models to find which model is the best fit for the release profile obtained.

\section{Scanning electron microscopy (SEM)}

The SEM analysis was carried out by mounting the samples on the stub using double sided adhesive tape and sputter coated with platinum using a sputter coater (Edward S 150, $\mathrm{UK})$. The coated tablets were observed under SEM (JEOL, JSM-6360, Kyoto, Japan) at room temperature. The acceleration voltage used was $10 \mathrm{kV}$ with the secondary electron image as a detector.

\section{RESULTS AND DISCUSSION}

The hydrogel based matrix tablets of crosslinked chitosan (CHAL1, CHAL2, CHAL3 and CHAL4) and HEC blend were prepared and evaluated for controlled release of GBP. There are number of crosslinking agents that can crosslink chitosan. Among them, aldehydes are the commonly used as crosslinking agents because they are inexpensive and easily available. The crosslinking ability and water retention efficiency of hydrogel depends on the crosslinking agent. The polymers having hydroxyl group need drastic conditions (low $\mathrm{pH}$, high temperature, etc) for crosslinking reactions with aldehydes whereas, polymers having amine groups can be crosslinked aldehydes under mild conditions through Schiff bases reactions.

In our earlier study, we reported the use of chitosan hydrogel prepared by different crosslinking agents like dextrose, ureaformaldehyde, sodium tripolyphosphate and acetaldehyde for controlled release of GBP 
Table I Composition of hydrogel matrix tablets

\begin{tabular}{lrrrrrrr}
\hline Ingredients (mg) & G1 & G2 & G3 & G4 & G5 & G6 & G7 \\
\hline GBP & 100 & 100 & 100 & 100 & 100 & 100 & 150 \\
CHAL1 & 150 & 150 & 150 & 0 & 0 & 0 & 0 \\
CHAL2 & 0 & 0 & 0 & 150 & 0 & 0 & 0 \\
CHAL3 & 0 & 0 & 0 & 0 & 150 & 0 & 0 \\
CHAL4 & 0 & 0 & 0 & 0 & 0 & 150 & 150 \\
HEC & 50 & 100 & 150 & 100 & 100 & 100 & 100 \\
MCC & 185 & 135 & 85 & 135 & 135 & 135 & 85 \\
Talc & 10 & 10 & 10 & 10 & 10 & 10 & 10 \\
Magnesium stearate & 5 & 5 & 5 & 5 & 5 & 5 & 5 \\
\hline
\end{tabular}
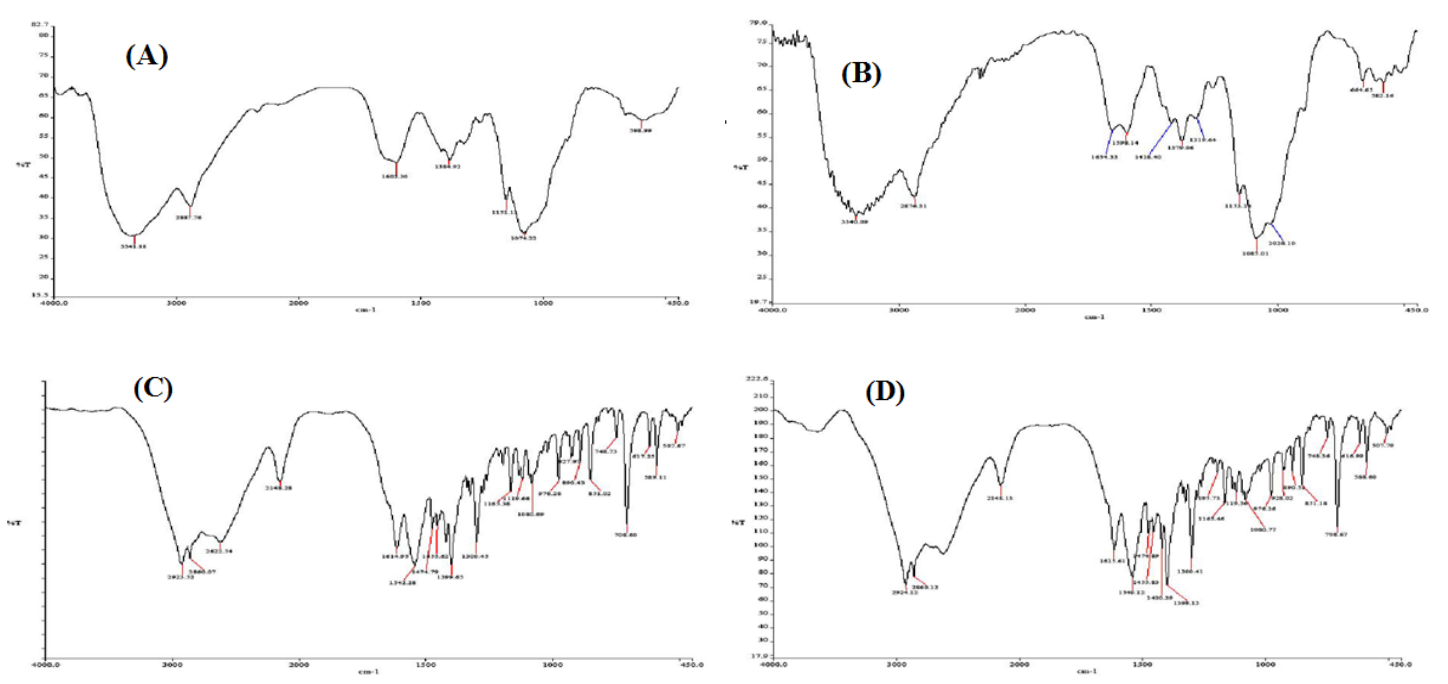

Figure 1. FTIR spectra of $\mathrm{CH}(\mathrm{A})$ and $\mathrm{CHAL} 3(\mathrm{~B})$, FTIR spectra of GBP (C) and physical mixture of GBP and other excipients (D)

(Managoli et al., 2012). Now, in this work, we are reporting the use of chitosan hydrogel prepared by crosslinking with acetaldehyde with a blend of HEC for controlled release of GBP. Chitosan hydrogels were prepared by crosslinking with AL, where the chitosan undergoes reaction with AL through Schiff base mechanism under mild conditions (Hemant et al., 2010).

\section{FTIR analysis}

The FTIR spectra of $\mathrm{CH}$ and CHAL2 are given in Figure 1 (A) and (B) respectively. In case of $\mathrm{CH}$, the peak at $3341 \mathrm{~cm}^{-1}$ is assigned for the stretching vibrations of hydroxyl and amino groups, the peak at 2887 $\mathrm{cm}^{-1}$ is due to stretching vibrations of $-\mathrm{CH}$ groups, the peak at $1602 \mathrm{~cm}^{-1}$ is due to the amino groups, and the peak at $1074 \mathrm{~cm}^{-1}$ is due to the ether group. While in case of CHAL2, peak at $3340 \mathrm{~cm}^{-1}$ is assigned for the stretching vibrations of hydroxyl groups, the peak at 2876 is due to stretching vibrations of $-\mathrm{CH}$ groups, the peak at $1654 \mathrm{~cm}^{-1}$ is due to carbonyl stretching vibration of acetamide group, peak at $1598 \mathrm{~cm}^{-1}$ due to imine bonds $(\mathrm{C}=\mathrm{N})$ formed by crosslinking reaction between the amino groups of chitosan and aldehyde groups of acetaldehyde. This peak confirms the formation of Schiff base after the crosslinking reaction. The stronger peak at $1085 \mathrm{~cm}^{-1}$ is assigned to ether group which was shifted slightly from 1074 to $1085 \mathrm{~cm}^{-1}$, this indicates the creation of a new open chain ether linkages in the crossed linked chitosan. 

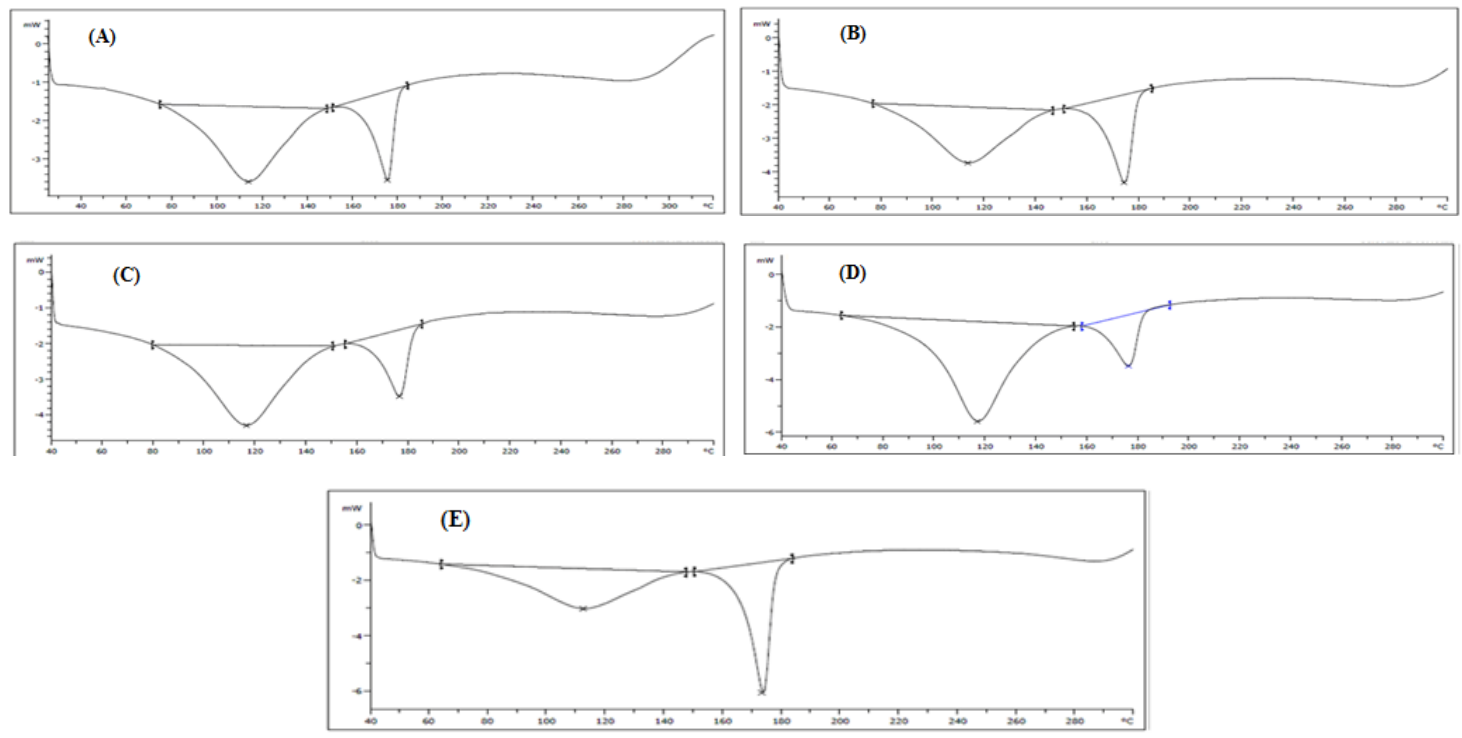

Figure 2. DSC thermograms of G2 (A), G4 (B), G5 (C), G6 (D) and G7 (E)

Figure $1(\mathrm{C})$ and $(\mathrm{D})$ depicts the FTIR spectra of GBP and physical mixture of GBP and other excipients respectively. The peaks at 2923 and $2860 \mathrm{~cm}^{-1}$ are due to $\mathrm{NH}^{3+}$ stretching vibrations, however there was no peak absorption in the usual -NH stretching regions $\left(3500-3300 \mathrm{~cm}^{-1}\right)$. The peak at $2148 \mathrm{~cm}^{-1}$ is due to the distinct side chain and/or C-N stretching vibrations of GBP polymorphs. The peaks at 1614 and $1542 \mathrm{~cm}^{-1}$ could be assigned as the ionized asymmetric carboxylate and $\mathrm{NH}^{3+}$ deformation vibration. The peaks at 1474 , $1455,1399,1300 \mathrm{~cm}^{-1}$ are corresponded also to the asymmetric carboxylate band and/or $\mathrm{CH}_{2}$ deformation band. Whereas, in the spectra of physical mixture of GBP and other excipients, the same characteristics peaks related to GBP were noticed with slight variations. This confirms the compatibility of GBP in the formulation.

\section{DSC analysis}

The DSC thermograms are shown in Figure 2. G2, G4, G5, G6 and G7 have shown endothermic peaks at 110.86, 115.52, 118.50, 120.78 and $116.55^{\circ} \mathrm{C}$ respectively. This may due to the evaporation of associated water from the hydrogel matrix. While, the second endothermic peaks at 174.50, 176.13, 178.50, 180.17 and $175.39^{\circ} \mathrm{C}$ may be related to the decomposition of the hydrogel matrix. In all the hydrogels, a shift in endothermic peaks was observed towards higher temperature. The order of endothermic peaks was G6 > G5 > G4 > G2. This shift in endothermic peak towards higher temperature could be due to the formation of stronger hydrogel network as a result of crosslinking. While in case of $\mathrm{G} 7$, the endothermic peak was shifted to lower temperature quite relatively, which may be due to the excess drug loading that looses the strength of the hydrogel matrix.

\section{TG analysis}

The TGA thermograms of $\mathrm{CH}$, CHAL2, CHAL3 and CHAL4 are shown in figure 3. In case of $\mathrm{CH}$ (A), weight loss of $10.88 \%$ up to $180^{\circ} \mathrm{C}$ was observed and is due to loss of associated water present in the polymer network and above $300^{\circ} \mathrm{C}$ it started decomposing, attributing to the degradation of polymer network, and weight loss reached a value of $100 \%$ at $500^{\circ} \mathrm{C}$. The weight loss in case of CHAL2 (B) was $13.78 \%$ up to $160^{\circ} \mathrm{C}$, due to the loss of water present in the polymer and further, weight loss reached a value of $72 \%$ at $600^{\circ} \mathrm{C}$, due to decomposition of polymer matrix. Similar pattern was observed with CHAL3 (C), with an initial weight loss of $12.91 \%$ at $140{ }^{\circ} \mathrm{C}$ and it reached value of $67 \%$ at 

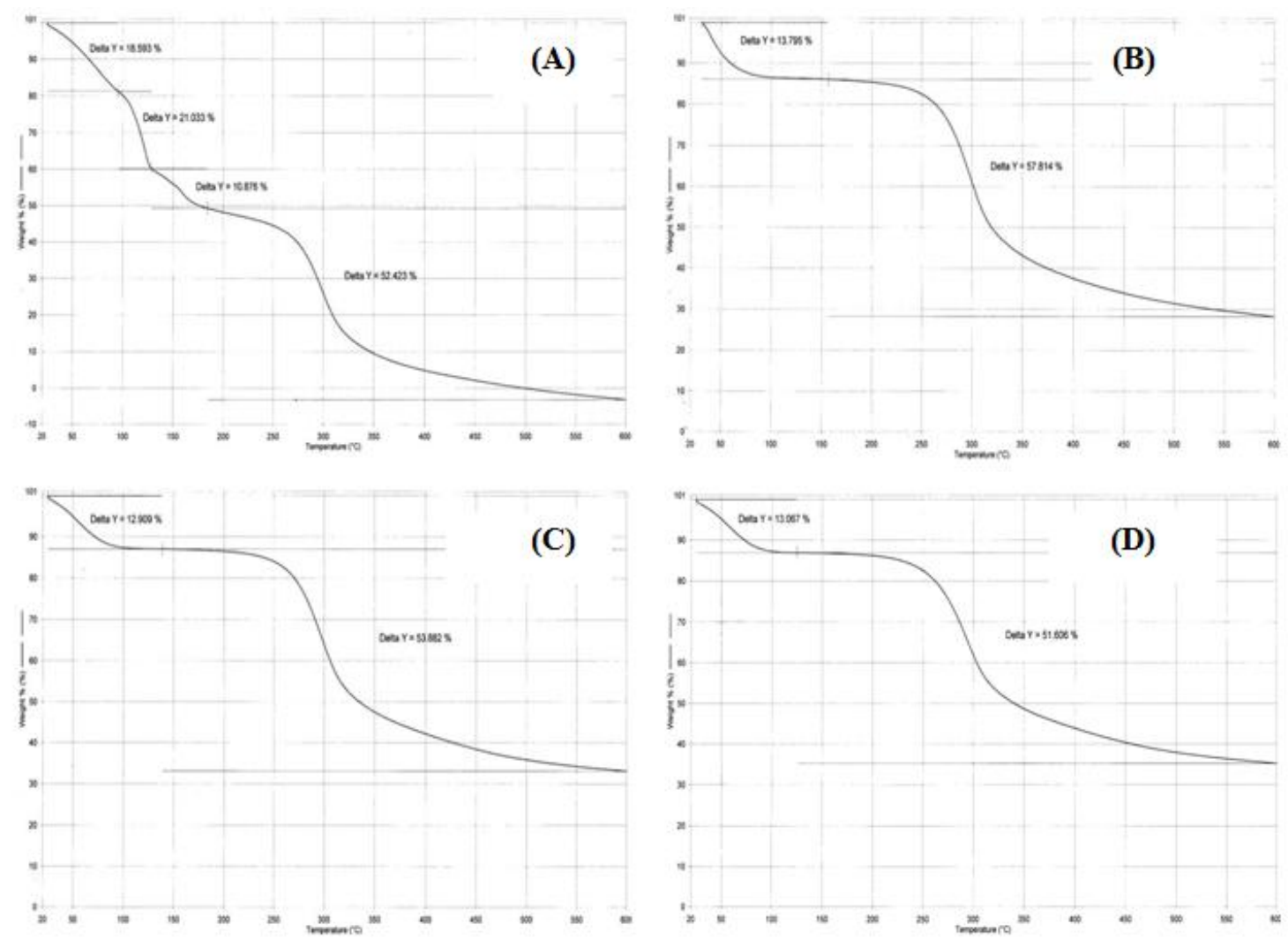

Figure 3. TGA thermograms of $\mathrm{CH}(\mathrm{A}), \mathrm{CHAL2}(\mathrm{B}), \mathrm{CHAL3}(\mathrm{C})$ and CHAL4 (D).

$600^{\circ} \mathrm{C}$. Whereas, CHAL4 (D) showed an initial weight loss of $13.07 \%$ at $125^{\circ} \mathrm{C}$ and finally it reached a value of $64 \%$ at $600^{\circ} \mathrm{C}$. From this study, it can be said that the thermal stability was in the order of CHAL4 > CHAL3 > CHAL2 $>\mathrm{CH}$. This increase in thermal stability indicates the formation of stronger hydrogel network as a result of crosslinking.

\section{X-ray diffraction studies}

The XRD studies are useful to examine the crystallinity of the polymer as crystallinity increases with stiffer polymer network. The Xray diffractograms of formulations G2, G4, G5, G6 and G7 are presented in figure 4. All the samples have shown peaks between $2 \theta$ of $15^{\circ}$ and $25^{\circ}$ due to the crystallinity. The percentage crystallinity was $7.6 \%, 8.6 \%, 9.5 \%, 11.9 \%$ and $11.7 \%$ for G2, G4, G5, G6 and G7 respectively. The crystallinity was in the order of $\mathrm{G} 6>\mathrm{G} 7>\mathrm{G} 5>\mathrm{G} 4>\mathrm{G} 2$. This order of crystallinity, consistent with the results of DSC and TGA, which indicates that the crystallinity increases with crosslinking and that, may be attributed to increased stiffness of the hydrogel network.

\section{Evaluation of tablets}

The results obtained from evaluation of granules advocates that the granules have good flow properties with an angle of repose values less than $35^{\circ}$. A good packing ability of the granules was also indicated by Carr's compressibility index and Hausner ratio since the values were in the range of 12.19 to 15.21 and 1.122 to 1.152 respectively. The weight and drug contents of all the tablets were within the range of $502 \mathrm{mg}$ to $509 \mathrm{mg}$ and $95.50 \%$ to $98.76 \%$ respectively and were found to be within the specified range. The hardness and friability were in the range of 5.3 to $6.0 \mathrm{~kg} / \mathrm{cm}^{2}$ and $0.21 \%$ to $0.86 \%$ respectively, indicating the sufficient mechanical strength of the prepared hydrogel tablets. 

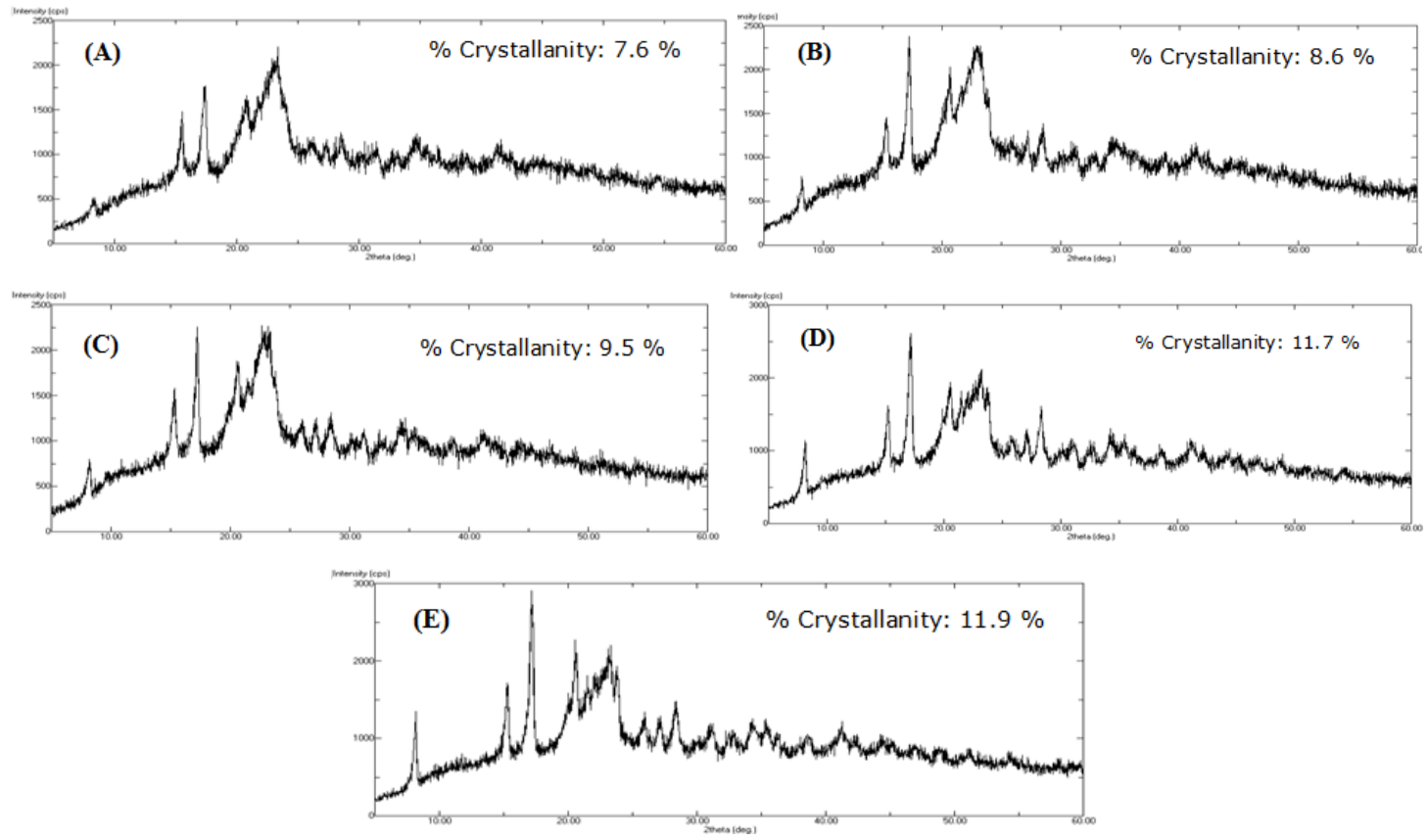

Figure 4. X-ray diffractograms of G2 (A), G4 (B), G5 (C), G6 (D) and G7 (E).

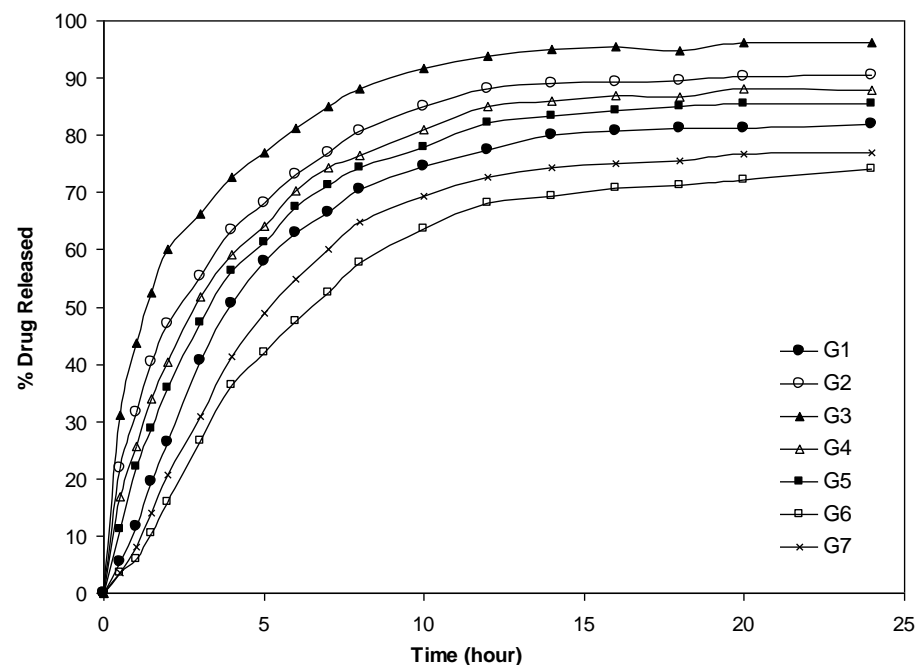

Figure 5. Drug release profiles of hydrogel matrix tablets

It was observed from the results of equilibrium swelling study that the swelling of hydrogel tablets depends upon the crosslinking of chitosan and concentration of HEC. As the amount of HEC was increased, the swelling of tablets was increased, which may be due to decreased stiffness of the hydrogel network. On the other hand, as the crosslinking of chitosan was increased, the swelling was decreased due to increased stiffness of network as a result of increased crosslink density (Kulkarni et al., 2011, Boppana et al., 2010). The swelling of hydrogel tablets was in the order G3 $>\mathrm{G} 2>\mathrm{G} 1>\mathrm{G} 4>\mathrm{G} 5>\mathrm{G} 7>\mathrm{G} 6$ and this is in agreement with the results of XRD, DSC and TGA. As the stiffness decreases swelling is expected to increase. We also noticed that the swelling of the hydrogel tablets was higher in 

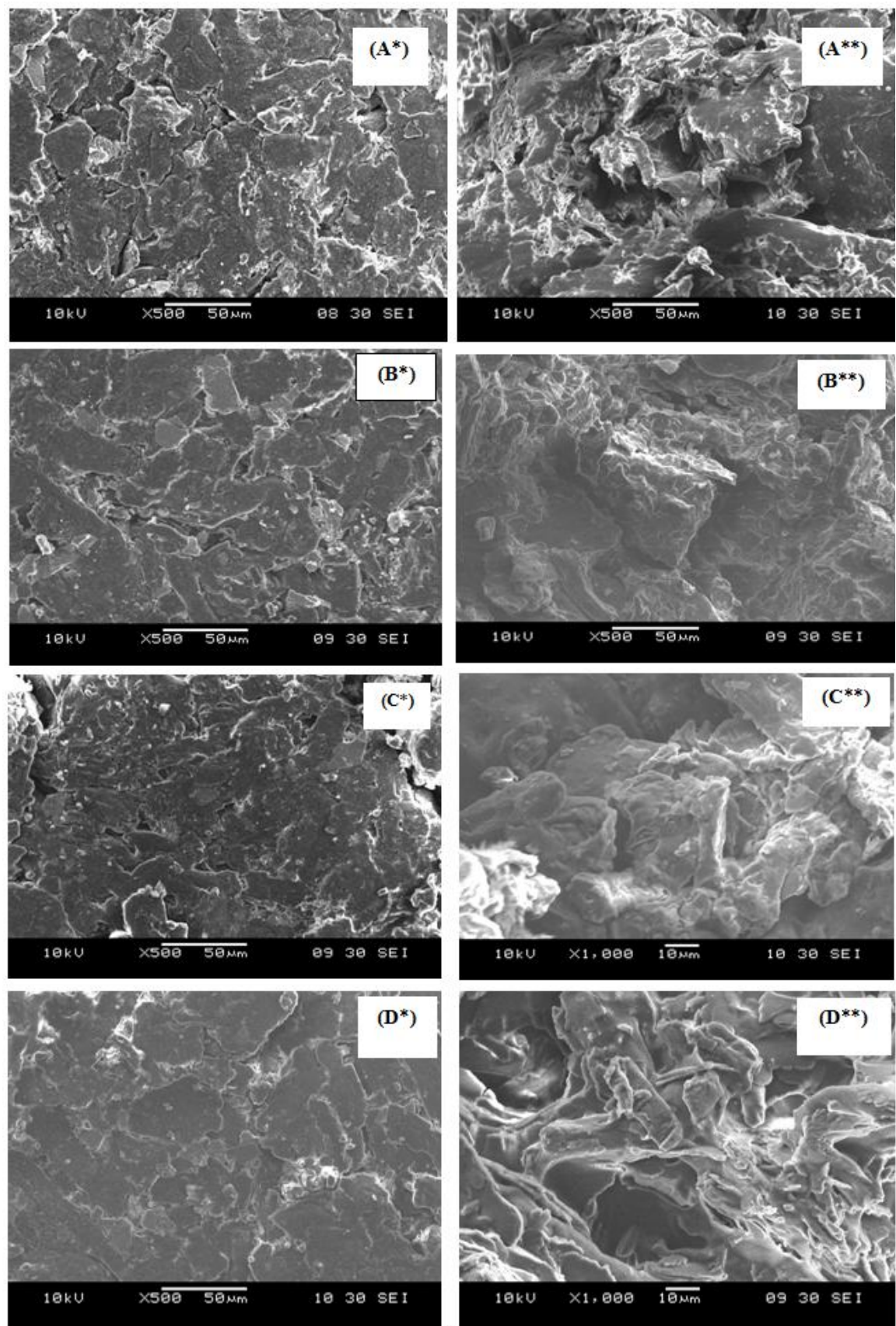

* Before dissolution testing. ** After dissolution testing.

Figure 6. SEM photomicrographs of hydrogel matrix tablets G2 (A), G4 (B), G5 (C) and G6 (D) before $\left(^{*}\right)$ and after $(* *)$ the dissolution studies.

the solution of $\mathrm{pH} 1.2$ as compared to the swelling in the solution of $\mathrm{pH}$ 7.4. It may be due to hydration of cations, formed by basic amino groups of chitosan under acidic condition.
The drug release behaviour of hydrogel tablets is shown in igure 5 . The tablets have shown drug release up to $24 \mathrm{~h}$ depending upon the formulation variables. The crosslinking of chitosan and amount of HEC directly affected of the drug release rate. As the amount of HEC 
was increased, the drug release rate from the tablets was increased; which can be attributed to increased swelling of the hydrogel network. On the other hand, as the crosslinking of chitosan was increased, we noticed decreased drug release. This could be due to the formation of stiffer hydrogel matrix at higher crosslink densities by decreasing the free volume of the matrix, thereby reducing the movement of drug molecules through the polymer network (More et al., 2010, Kulkarni et al., 2012). It was also noticed that the increase in initial drug loading increased the drug release. The drug release rate from the hydrogel tablets was in the order G3>G2>G1>G4 $>\mathrm{G} 5>\mathrm{G} 7>\mathrm{G} 6$, this order is also supported by XRD, DSC and TGA results.

The drug release data was fitted to the following empirical equation (Ritger et al., 1997) to calculate the mechanism of drug release:

$$
\frac{M t}{M \infty}=K t^{n}
$$

where $M_{\mathrm{t}}$ is the amount of drug released at time $t, M_{\infty}$ is the total amount of drug loaded, $K$ is constant and $n$ values are the indication of the type of release mechanism. The calculated $n$ values were in the range of 0.52 to 0.68 . The $n$ values were dependent on crosslinking of chitosan and amount HEC; as the amount of HEC was increased, the $n$ values were decreased and as crosslinking of chitosan was increased, the $n$ values were increased. This suggests that the mechanism of drug release from hydrogel tablets follows non-Fickian transport (Ritger et al., 1997).

\section{SEM results}

The surface morphology of the hydrogel tablets before and after the dissolution testing was studied using SEM analysis and are shown in Figure 6. The surface of the hydrogel tablets before drug release testing was smooth and uniform. While, after the drug release study, the surface of the tablets has become porous and dense with some polymeric erosion. This indicates that the hydrogel network has undergone swelling and drug might have diffused out through the matrix by polymer chain relaxation and erosion.

\section{CONCLUSIONS}

The hydrogel based matrix tablets of cross-linked chitosan and HEC blend were prepared and evaluated for controlled release of GBP. The weight and drug contents of all the tablets were found to be uniform. The hardness and friability were within specified range. The matrix tablets were competent to release the drug for $24 \mathrm{~h}$ depending upon the formulation variables. As the concentration of HEC was increased in the tablets, the drug release was also increased. This may be due to decreased stiffness of the hydrogel matrix. On the other hand, as the crosslinking of chitosan was increased, the drug release was decreased, which may be due to increased stiffness of the matrix. Drug release mechanism followed nonFickian transport. This study demonstrated that the blend hydrogel matrix of crosslinked chitosan and HEC could be a versatile drug delivery system for controlled release of GBP.

\section{ACKNOWLEDGEMENTS}

Authors appreciate the kind help and support of Dr. K.G. Akamanchi, UDCT, Mumbai in completion of this project. Authors are also thankful to the management of BVVS's Shri. HSK College of Pharmacy, Bagalkot, India and BLDEA's College of Pharmacy, Bijapur, India for providing facilities to carry out this work.

\section{REFERENCES}

Boppana R., Kulkarni RV., Mutalik SS., Setty CM., Sa B. 2010. Interpenetrating network hydrogel beads of carboxymethylcellulose and egg albumin for controlled release of lipid lowering drug. J. Microencapsu. 27: 337-344.

Bryans JS., Wustrow DJ. 1999. 3-substituted GABA analogs with central nervous system activity. Med.Res. Rev. 19: 149-177.

Chen LY., Tian ZG., Du YM. 2004. Synthesis and $\mathrm{pH}$ sensitivity of carboxymethyl chitosan-based polyampholyte hydrogels for protein carrier matrices. Biomaterials, 25: 3725-3732.

Drury JL., Mooney DJ. 2003. Hydrogels for tissue engineering: scaffold design variables and applications. Biomaterials, 24: 4337-4351. 
Draget KI., Varum KM., Moen E., Gynnild H., Smidsrod O. 1992. Chitosan crosslinked with Mo[VI] polyoxyanions: a new gelling system. Biomaterials, 13: 635-641.

Gong HP., Zhong YH., Li JC., Gong YD., Zhao NM., Zhang XF. 2000. Studies on nerve cell affinity of chitosan-derived materials. J. Biomed. Mater. Res. 52: 285295.

Hemant KSY., Shivakumar HG. 2010. Development of chitosan acetate films for transdermal delivery of propranolol hydrochloride. Tropical J. Pharm. Res. 9: 197-203.

Hoffman AS. 2002. Hydrogels for biomedical applications. Adv. Drug Delivery Rev. 43: 312

Kim JH., Kim JY., Lee YM., Kim KY. 1992. Controlled release of riboflavin and insulin through crosslinked poly(vinyl alcohol)/chitosan blend membrane. J.Appl. Polym. Sci. 44: 18231828.

Kulkarni VH., Keshavayya J., Shastri CS. 2005. Transdermal delivery of antiasthmatic drug through modified chitosan membrane. Ind. J. Pharm. Sci. 67: 544-547.

Kulkarni RV., Baraskar VV., Setty CM., Sa B. 2011. Interpenetrating polymer network matrices of sodium alginate and carrageenan for controlled drug delivery application. Fibers and Polym. 12: 352-358.

Kulkarni RV., Mutalik S., Mangond BS., Nayak UY. 2012. Novel interpenetrated polymer network microbeads of natural polysaccharides for modified release of water soluble drug: in-vitro and in-vivo evaluation. J. Pharm. Pharmacol. 64: 530540.

Lin-Gibson S., Walls HJ., Kennedy SB., Welsh ER. 2003. Reaction kinetics and gel properties of blocked diisocyinate crosslinked chitosan hydrogels. Carbobydrate Polym. 54: 193-199.

Managoli NS., Kulkarni RV., Ramarao N., Muchandi IS. 2012. Crosslinked chitosan hydrogel matrix tablets for controlled release of gabapentin. Farmacia, 60: 272286.

More SM., Kulkarni RV., Sa B., Kalyane NV. 2010. Glutaraldehyde-crosslinked poly(vinyl alcohol) hydrogel discs for the controlled release of antidiabetic drug. $J$. Appl. Polym. Sci. 116: 1732-1738.

Mutalik S., Manoj K., Reddy MS., Kushtagi P., Nayak U., Anju P., Ranjith A., Udupa N. 2008. Chitosan and enteric polymer based once daily sustained release tablets of aceclofenac: In vitro and in vivo studies. AAPS PharmSciTech, 9: DOI: 10.1208/s12249-008-9075-3.

Pavithra TK., Harshitha R., Panneer K., Renuka S., Prakash Rao B., Narendra C. 2010. Formulation and evaluation of hydrogel based oral controlled drug delivery system for antihypertensive drug. J. Pharm. Sci. Tech. 2: 276-283.

Ravi Kumar MNV. 2000. A review of chitin and chitosan applications. React. Funct. Polym. 46: 1-27.

Ritger PL., Peppas NA. 1997. A simple equation for description of solute release: II. Fickian and anomalous release from swellable devices. J. Control. Release, 5: 3742.

Singh A., Narvi SS., Dutta PP., Pandey ND. 2006. External stimuli response on a novel chitosan hydrogel crosslinked with formaldehyde. Bull. Mater.Sci.29: 233-238.

Zhao L., Mitomo H., Zhai M., Yoshii F., Nagasawa N., Kume T. 2003. Synthesis of antibacterial PVA/CM-chitosan blend hydrogels with electron beam irradiation. Carbobydrate Polym. 53: 439-446. 